\title{
Investigation of Underground Sour Gas Storage in a Depleted Gas Reservoir
}

\author{
R. Azin ${ }^{1,2 *}$, R. Malakooti², A. Helalizadeh ${ }^{3}$ and M. Zirrahi ${ }^{4}$ \\ 1 Department of Chemical Engineering, School of Engineering, Persian Gulf University, Bushehr 7516913817 - Iran \\ 2 Persian Gulf Science and Technology Park, Bushehr - Iran \\ 3 Department of Petroleum Engineering, Petroleum University of Technology, Ahwaz - Iran \\ 4 Department of Chemical \& Petroleum Engineering, Schulich School of Engineering, University of Calgary, Calgary, \\ Alberta, Canada T2N IN4 - Canada \\ e-mail: reza.azin@pgu.ac.ir -reza.malakoot@@et.hw.ac.uk-helalizadeh@yahoo.com - mzirrahi@ucalgary.ca \\ * Corresponding author
}

Résumé - Étude de stockage souterrain de gaz naturel acide dans un réservoir épuisé Le Stockage Souterrain de Gaz (SSG) implique le stockage de grandes quantités de gaz naturel pour satisfaire la demande en gaz naturel des secteurs domestiques, commerciaux ou industriels. Le stockage du gaz naturel acide peut être avantageux du point de vue économique car il réduit les coûts de traitement et augmente le potentiel d'exploitation de réservoirs partagés.

Cet article étudie la faisabilité du SSG dans un gisement iranien fracturé et épuisé de gaz à condensat. La simulation compositionnelle est utilisée pour construire le modèle dynamique de réservoir, développer la phase d'adaptation de l'histoire d'exploitation et établir les cycles d'Injection/Soutirage (I/S). Un flux de gaz peu corrosif et trois flux de gaz acide de compositions différentes ont été testés pour stockage dans le réservoir pendant une période estivale.

Les résultats de simulation montrent que la présence de sulfure d'hydrogène et de dioxyde de carbone dans le flux de gaz injecté améliore la production de condensats. L'Amélioration de Production de Condensats (APC), définie comme le pourcentage d'augmentation de la récupération de condensats grâce à l'injection de gaz acide par rapport à l'injection de gaz peu corrosif, a été calculée pour les différentes compositions du gaz stocké. Le Taux de Contenance en Condensats (TCC), défini comme le rapport entre la production de condensats dans le gaz acide soutiré et celle dans le méthane soutiré, a été également évalué pour les différentes compositions de gaz stocké. Les résultats ont montré que l'APC a des taux plus élevés pendant les premiers cycles, mais qu'elle diminue dans les derniers. Le TCC est plus élevé pour le gaz acide comparativement au gaz peu corrosif. De plus, le pouvoir calorifique du gaz produit, calculé pour tous les cycles d'injection/soutirage, est comparé avec celui du gaz injecté. Il est apparu que la différence de pouvoir calorifique entre le gaz produit et le gaz injecté augmente avec la teneur en sulfure d'hydrogène et dioxyde de carbone du gaz injecté. En outre, il est aussi apparu que le réservoir possède, à la fin des cycles d'injection/soutirage, une pression plus basse dans le cas du stockage souterrain de gaz acide que dans celui de gaz peu corrosif. La présence des composants acides fait baisser le coefficient $z$ du flux de gaz injecté et induit une différence plus faible entre le coefficient $z$ du gaz injecté et celui du fluide de réservoir.

Abstract - Investigation of Underground Sour Gas Storage in a Depleted Gas Reservoir Underground Gas Storage (UGS) involves storage of large quantities of natural gas to support the natural gas demand in domestic, commercial and industrial areas. Storage of sour gas can be advantageous from economic standpoint, as it reduces treatment costs and increases the potential of 
production from shared reservoirs. This paper investigates feasibility of UGS in one of Iranian depleted fractured gas condensate reservoirs. Compositional simulation was employed to build dynamic reservoir model, develop the history matching phase of the reservoir and construct Injection/Withdrawal (I/W) cycles. One sweet gas stream and three sour gas streams with different compositions were tested for storage into reservoir during summer season.

Results of simulation showed that presence of $\mathrm{H}_{2} \mathrm{~S}$ and $\mathrm{CO}_{2}$ in the injected gas stream improves condensate production. Condensate Production Enhancement (CPE), defined as the percentage of condensate recovery increase due to sour gas injection relative to the sweet gas injection, was calculated for different compositions of storage gas. Also, Condensate Holding Ratio (CHR), defined as the ratio of condensate in the withdrawn sour gas to that in the withdrawn $\mathrm{CH}_{4}$, was estimated for different storage gas compositions. Results showed that CPE has a higher rate in earlier cycles and declines at later cycles. CHR is higher for sour gas storage compared to sweet gas. Furthermore, heating value of produced gas was calculated in all I/W cycles and compared with heating value of injected gas. It was indicated that difference between heating value of produced and injected gas increases with increase of $\mathrm{H}_{2} \mathrm{~S}$ and $\mathrm{CO}_{2}$ content of the injected gas.

Also, it was found that the reservoir has lower pressure rise at the end of $I / W$ cycles in the case of underground sour gas storage compared to sweet gas storage. The presence of acid gas components decreases the z-factor of injected gas stream resulting in smaller difference between z-factors of injected gas and reservoir fluid.
Abbreviations
CHR Condensate Holding Ratio
CPE Condensate Production Enhancement
EOS Equation of State
I/W Injection/Withdrawal
PR Peng-Robinson
PVT Pressure Volume Temperature
UGS Underground Gas Storage

\section{Nomenclature}

$N p_{s o} \quad$ Cumulative condensate production with sour gas injection $\left(\mathrm{m}^{3}\right)$

$N p_{s w} \quad$ Cumulative condensate production with sweet gas injection $\left(\mathrm{m}^{3}\right)$

$K_{\mathrm{C}_{5+}}^{\text {pure }} \quad K$-value of condensate $\left(\mathrm{C}_{5+}\right)$ in injected pure methane (dimensionless)

$K_{\mathrm{C}_{5+}}^{\text {sour }} \quad K$-value of condensate $\left(\mathrm{C}_{5+}\right)$ in injected sour gas (dimensionless)

$P_{p c} \quad$ Pseudo-critical pressure $(\mathrm{Pa})$

$P_{p c}^{\prime} \quad$ Pseudo-critical pressure adjusted for nonhydrocarbon components $(\mathrm{Pa})$

$T_{p c} \quad$ Pseudo-critical temperature $\left({ }^{\circ} \mathrm{C}\right)$

$T_{p c} \quad$ Pseudo-critical temperature adjusted for nonhydrocarbon components $\left({ }^{\circ} \mathrm{C}\right)$

$x_{\mathrm{C}_{5+}}^{\text {pure }} \quad$ Liquid mole fraction of condensate $\left(\mathrm{C}_{5+}\right)$ in injected pure methane (dimensionless)

$x_{\mathrm{C}_{5+}}^{\text {sour }} \quad$ Liquid mole fraction of condensate $\left(\mathrm{C}_{5+}\right)$ in injected sour gas (dimensionless)

$y_{\mathrm{H}_{2} \mathrm{~S}} \quad$ Mole fraction of component $\mathrm{H}_{2} \mathrm{~S}$ (dimensionless)
$y_{\mathrm{C}_{5+}}^{\mathrm{CH}_{4}} \quad$ Vapor mole fraction of condensate $\left(\mathrm{C}_{5+}\right)$ in injected pure methane (dimensionless)

$y_{\mathrm{C}_{5+}}^{i n j} \quad$ Vapor mole fraction of condensate $\left(\mathrm{C}_{5+}\right)$ in injected gas (dimensionless)

$y_{\mathrm{C}_{5+}}^{\text {pure }} \quad$ Vapor mole fraction of condensate $\left(\mathrm{C}_{5+}\right)$ in injected pure methane (dimensionless)

$y_{\mathrm{C}_{5+}}^{\text {sour }} \quad$ Vapor mole fraction of condensate $\left(\mathrm{C}_{5+}\right)$ in injected sour gas (dimensionless)

$\varepsilon \quad$ Pseudo-critical temperature adjustment factor for nonhydrocarbon components $\left({ }^{\circ} \mathrm{C}\right)$

\section{INTRODUCTION}

Underground Gas Storage (UGS) is the unique efficient process to store large quantities of natural gas in an underground inventory. This technology has been adopted in many countries to match the constant supply from longdistance pipelines to the variable demand of markets. Depleted gas reservoirs represent the best candidates for UGS, in which natural gas is injected into the reservoir in the low-demand season, while it is withdrawn from the reservoir in the high-demand season [1]. Previous studies [2-4] focused on underground sweet gas storage in depleted gas reservoirs. In addition to sweet gas injection, sour gas, a blend of natural gas, hydrogen sulfide $\left(\mathrm{H}_{2} \mathrm{~S}\right)$ and carbon dioxide $\left(\mathrm{CO}_{2}\right)$ streams, can be recognized as another option for the purpose of UGS.

Underground sweet gas storage causes double costs in the industry. First, the sour gas stream is sweetened before injection into the reservoir; second, the withdrawn gas is usually contaminated with the fluid remaining in the reservoir 
and needs treatment before use. On the other hand, underground sour gas storage is a more economic option for UGS projects because the sweetening and treating process is performed once. This advantage brings about strategic management for shared gas reservoirs which contain sour gas. In this manner, the rate of gas withdrawal would be higher from the shared reservoirs since operators do not need to construct treatment facilities before reinjection of the produced gas.

When gas is stored in depleted gas condensate reservoirs, it can enhance the condensate recovery through pressure maintenance and gas cycling. Injection of dry gas increases the dew point pressure and helps revaporization of heavy hydrocarbon fractions into the gas phase [5]. Among all gases, pure $\mathrm{CO}_{2}$ and separator gases containing $\mathrm{H}_{2} \mathrm{~S}$ and $\mathrm{CO}_{2}$ are the most effective injection streams to minimize the condensate drop-out in near-wellbore zones [6]. Also, the presence of $\mathrm{CO}_{2}$ and $\mathrm{H}_{2} \mathrm{~S}$ in the gas phase causes water content and condensate holding to increase. Decrease in the compressibility factor is another impact of acid gases present in the injection gas [7]. Based on compositional simulation, $\mathrm{CO}_{2}$ is found to be an efficient dry gas stream that can be injected into the retrograde reservoir to improve condensate recovery [8]. Changes in the wetting behavior of reservoir rock and interfacial tension between the storage gas and reservoir fluid are other important issues that arise during UGS. Melean et al. [9] investigated the influence of gas/condensate interfacial tension and wetting behavior of condensate on the porous substrate. They found that $\mathrm{CO}_{2}$ is more advantageous than $\mathrm{CH}_{4}$ and $\mathrm{N}_{2}$ in reducing capillary forces and promoting the spreading of the condensate phase on water.

Sour natural gas mixtures result in problems arising mainly in two ways: increased potential for corrosion in wellbore and surface facilities and increased tendency for hydrate formation at elevated pressures [10]. These issues imply that all aspects of sour gas mixtures including their advantages and disadvantages must be considered whether or not underground sour gas storage is an economic and efficient process.

The main purpose of this work was to analyze the influence of $\mathrm{CO}_{2}$ and $\mathrm{H}_{2} \mathrm{~S}$ on the gas condensate reservoir behavior when subjected to underground sour gas storage. Injection/ Withdrawal scenarios with different $\mathrm{CO}_{2}$ and $\mathrm{H}_{2} \mathrm{~S}$ compositions were studied to find out the changes in the condensate recovery, heating value and reservoir pressure in the case of sour gas storage.

\section{METHODOLOGY}

\subsection{Reservoir Summary}

An Iranian depleted fractured gas reservoir was nominated to study the possibility of underground sour gas storage.
The reservoir's characteristics and production history information have been addressed in previous studies by Azin et al. [2] and Jodeyri Entezari et al. [3].

Figures 1 and 2 show the relative permeability curves of water, condensate and gas phases present in the reservoir. The capillary pressure curve between water and condensate phases versus water saturation is shown in Figure 3. The capillary pressure between gas and liquid phases was assumed to be zero. There was no active aquifer for this reservoir.

The condensate saturation in blocks is very low and does not exceed more than 0.001 during long-term production.

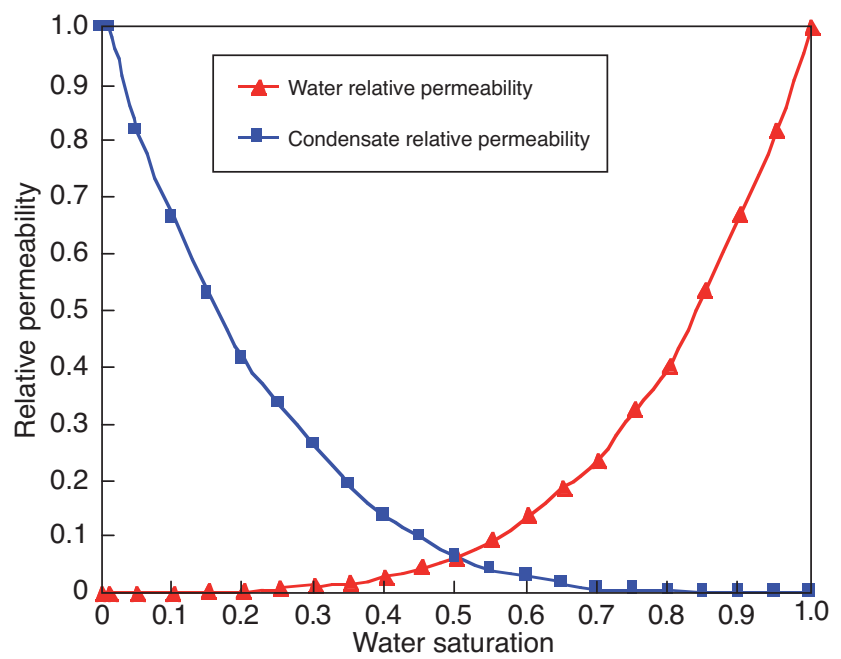

Figure 1

Typical relative permeability curves of water and condensate phases.

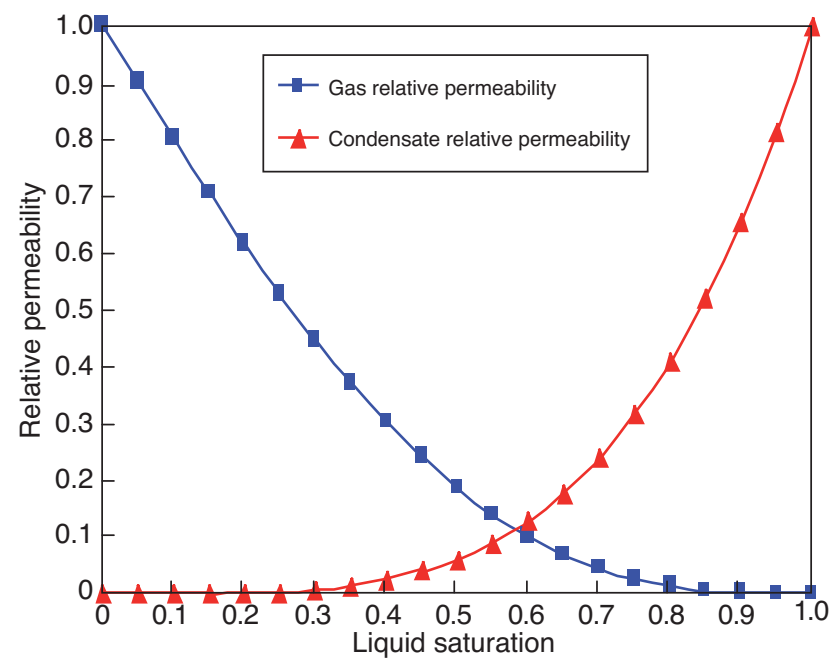

Figure 2

Typical relative permeability curves of gas and condensate phases. 


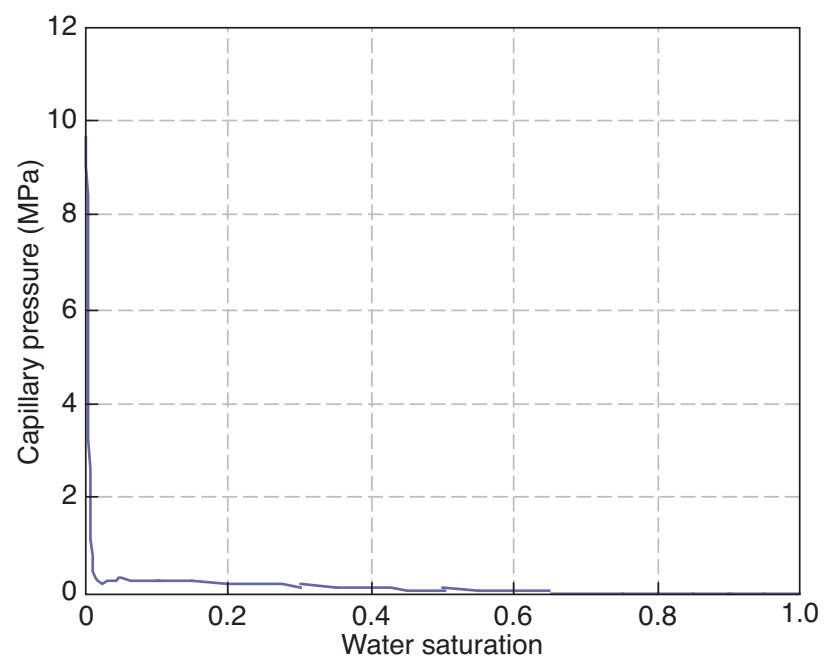

Figure 3

Capillary pressure curve versus water saturation.

Figure 2 shows that the liquid saturation should be about 0.25 in order to flow. This necessitates a condensate saturation of about 0.05 , which is difficult to achieve in reservoir simulation. This observation confirms that condensate presents within the reservoir as an immobile phase and only gas is considered to be a mobile phase. Difference in the condensate components' chemical potential in gas and liquid phases leads to condensate evaporation into the gas phase. Then condensate components are separated from the withdrawn gas in the surface facilities.

The mechanism of fluid flow between the matrix and fracture throughout successive Injection/Withdrawal cycles can be summarized as: the injected gas stream diffuses into the matrix blocks and reaches equilibrium with immobile condensate components. Thus, the gas phase becomes rich as a result of this equilibrium and condensate component evaporation during injection and shut-in periods. Enriched gas diffuses from the matrix into the fracture and then is withdrawn from the reservoir in the production phase. Finally, condensate components are removed from stream production because of pressure reduction in the surface facilities.

\subsection{Reservoir Simulation Model}

Azin et al. [2] designed a simulation model in Eclipse software [11] to study the possibility of UGS in the candidate reservoir. To do that, petrophysics and geological information was used in order to set up a static model of the reservoir. The fractured carbonate gas reservoir with bottom water was discretized to yield grid block dimensions of approximately $111 \times 41$. To build a dual porosity model, the simulation zone was subdivided into 34 simulation layers in the vertical direction, with 17 layers belonging to fractures.

The reservoir fluid model was prepared using the PVTi module in Eclipse software [11]. Components of the initial reservoir fluid were lumped into 7 pseudo-component groups and are given in Table 1. Pressure Volume Temperature (PVT) calculations were performed with the 3-parameter PengRobinson Equation of State (EOS). The Lohrenz-Bray-Clark (LBC) viscosity correlation was utilized to obtain the viscosity of gas and liquid [11]. History matching was accomplished as a final stage of simulation model construction and a reasonable match was achieved for gas and condensate production rates and reservoir pressure [2].

TABLE 1

Initial reservoir fluid composition

\begin{tabular}{c|c}
\hline Components & Observed composition \\
\hline $\mathrm{C}_{1}, \mathrm{~N}_{2}$ & 0.92097 \\
\hline $\mathrm{C}_{2}, \mathrm{CO}_{2}$ & 0.05361 \\
\hline $\mathrm{C}_{3}, n \mathrm{C}_{4}$ & 0.01715 \\
\hline$i \mathrm{C}_{4}, n \mathrm{C}_{5}$ & 0.00265 \\
\hline $\mathrm{FC}_{6}$ & 0.00188 \\
\hline $\mathrm{C}_{7}, \mathrm{C}_{11}$ & 0.00338 \\
\hline $\mathrm{C}_{13+}$ & 0.00036 \\
\hline
\end{tabular}

\subsection{I/W Gas Storage Cycle Simulation}

I/W gas storage cycles were developed on a completed simulation model obtained by Azin et al. [2]. The strategy used to make the storage cycles was similar to that considered in the studies of Malakooti and Azin [4]. Regarding annual gas consumption during cold months, [16] exhibited total consumption of $68 \times 10^{9} \mathrm{~m}^{3}$ natural gas in Iran from November 1st in 2008 up to March $31^{\text {st }}$ in 2009. Hence, it was decided to withdraw $5.1 \times 10^{9} \mathrm{~m}^{3}$ gas in each cycle, which provided $7.5 \%$ of total natural gas consumption during five cold months. To reach this objective, the injection rate was set to $327.7 \mathrm{~m}^{3} / \mathrm{s}$ from April 15th to October 15th; then, the production rate was equal to $393.3 \mathrm{~m}^{3} / \mathrm{s}$ from November 1 st to March 31st of next year. For this reservoir with a given target rate, the base pressure was found to be about 15.86 MPa [4]. Abandonment reservoir pressure before I/W cycles can start is called base pressure.

At optimum conditions [4], four new vertical wells were defined at different parts of the reservoir in addition to the one existing vertical well to make the depletion phase faster and increase the reservoir capacity to produce such gas volume. Figure 4 represents the well productivity index trend during the depletion phase and successive I/W cycles. All wells were supposed to shut in from October 16th to October 


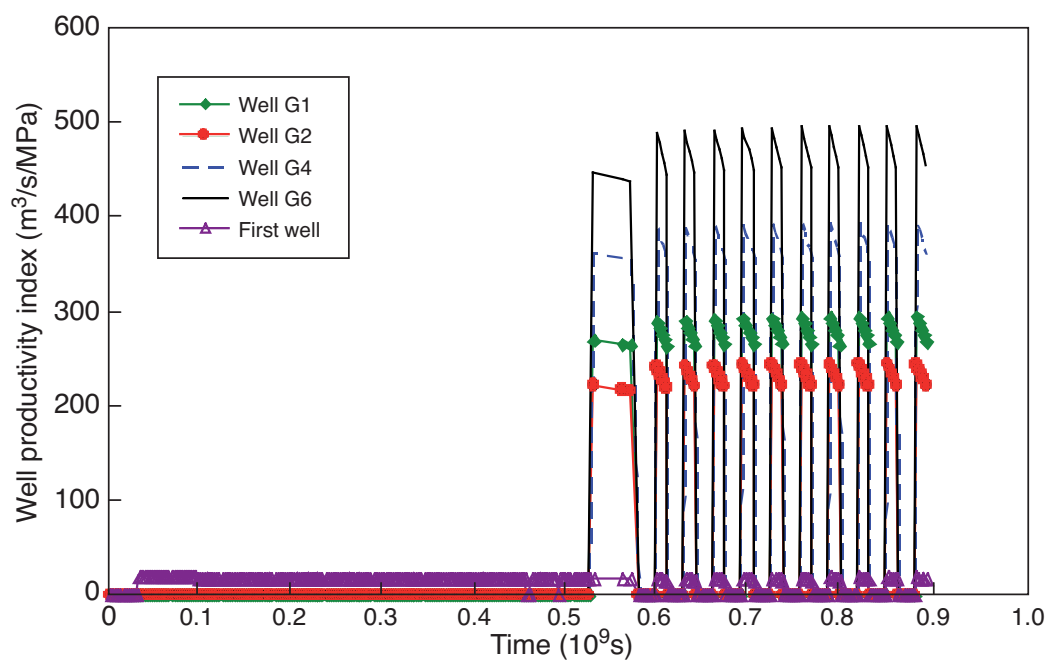

Figure 4

Well productivity index trend during depletion phase and successive I/W cycles.

TABLE 2

Composition of the injected gas streams

\begin{tabular}{c|c|c|c|c|c|c|c|c}
\hline Name & $\mathrm{C}_{1}, \mathrm{~N}_{2}$ & $\mathrm{C}_{2}, \mathrm{CO}_{2}$ & $\mathrm{C}_{3}, n \mathrm{C}_{4}$ & $i \mathrm{C}_{4}, n \mathrm{C}_{5}$ & $\mathrm{FC}_{6}$ & $\mathrm{C}_{7}, \mathrm{C}_{11}$ & $\mathrm{C}_{13+}$ & $\mathrm{H}_{2} \mathrm{~S}$ \\
\hline Sweet gas & 0.975 & 0.0246 & 0.0004 & 0 & 0 & 0 & 0 & 0 \\
\hline Sour gas (1) & 0.955116 & 0.034498 & 0.006978 & 0.000045 & 0.000001 & 0 & 0.000012 & 0.00335 \\
\hline Sour gas (2) & 0.906784 & 0.07742 & 0.008613 & 0.000047 & 0.000001 & 0 & 0.000013 & 0.007122 \\
\hline Sour gas (3) & 0.851784 & 0.12742 & 0.008613 & 0.000047 & 0.000001 & 0 & 0.000013 & 0.012122 \\
\hline
\end{tabular}

30th during each $\mathrm{I} / \mathrm{W}$ cycle. To examine the influence of sour gas streams on the performance of the UGS reservoir, four injection gas streams (one sweet gas stream and three sour gas streams) were used. The compositions of the storage gas streams are given in Table 2. The sweet gas stream was mainly composed of methane without any trace of $\mathrm{CO}_{2}$ and $\mathrm{H}_{2} \mathrm{~S}$, while the sour gas streams contained $\mathrm{CO}_{2}$ and $\mathrm{H}_{2} \mathrm{~S}$ with different compositions.

\section{RESULTS AND DISCUSSION}

\subsection{Effect of $\mathrm{H}_{2} \mathrm{~S}$ and $\mathrm{CO}_{2}$ Impurities on Condensate Evaporation}

The performance of underground sweet gas injection with different I/W schemes was studied previously [2-4]. It was shown that injection of sweet gas into a depleted gas condensate reservoir will increase the reservoir pressure in successive I/W cycles and cause the trapped condensate to revaporize. The results of this study indicate that condensate production tends to increase when sour gas is injected into the reservoir, as shown in Figure 5. Condensate Production Enhancement (CPE), defined by Equation (1), reveals the effect of sour compounds on the condensate production:

$$
C P E=\frac{N p_{s o}-N p_{s w}}{N p_{s w}}
$$

where:

$N p_{s o}$ : Cumulative condensate production with sour gas injection,

$N p_{s w}$ : Cumulative condensate production with sweet gas injection.

Figure 6 depicts the CPE trend versus successive I/W cycles for different sour gas stream compositions. For instance, at the end of the 10th cycle, $\mathrm{CPE}$ will be 3, 5 and 7 percent when the mole percent of $\left(\mathrm{CO}_{2}+\mathrm{H}_{2} \mathrm{~S}\right)$ in injected streams is $0.85,2.8$ and $8.3 \%$, respectively. This figure also indicates that the rate of CPE is not uniform; the rate is higher at initial stages and decreases in later cycles, where the remaining condensate trapped in the porous media becomes more difficult to extract by injected gas. 


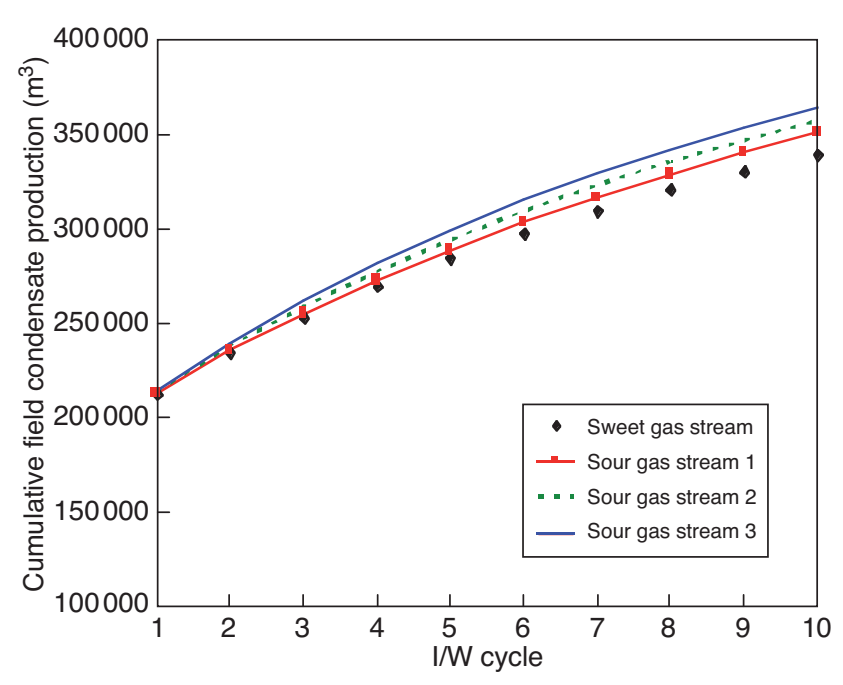

Figure 5

Field condensate production total in the case of different injected gas streams.

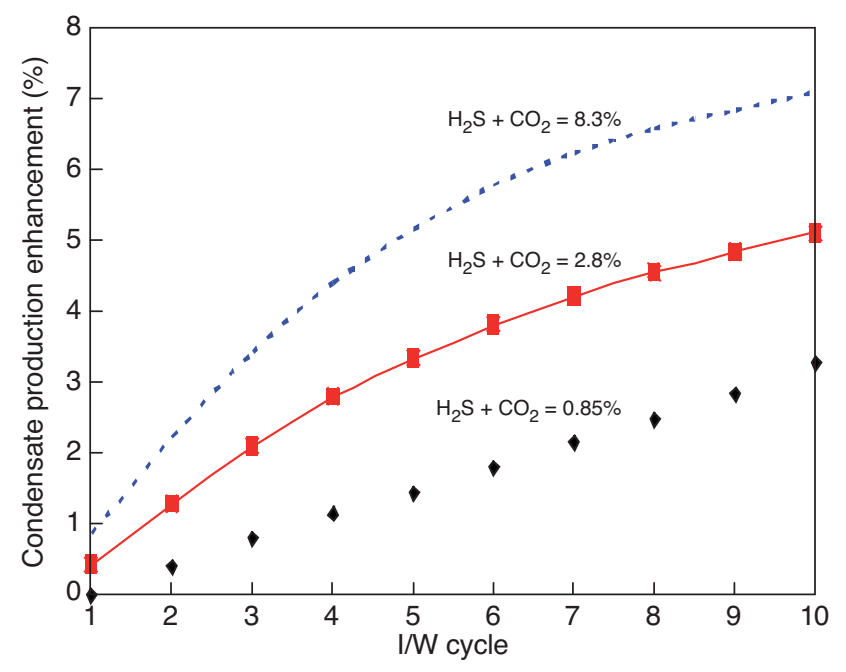

Figure 6

Condensate production enhancement caused by various mole fraction of $\mathrm{CO}_{2}$ and $\mathrm{H}_{2} \mathrm{~S}$.
According to Figures 5 and 6, the presence of $\mathrm{CO}_{2}$ and $\mathrm{H}_{2} \mathrm{~S}$ in the injection gas increases the tendency of heavy hydrocarbons to vaporize and produce during the withdrawal stage. One reason for this phenomenon is that $\mathrm{CO}_{2}$ and $\mathrm{H}_{2} \mathrm{~S}$ molecules have a potential to make London dispersion forces with heavy hydrocarbons. The oxygen and sulfur atoms of $\mathrm{CO}_{2}$ and $\mathrm{H}_{2} \mathrm{~S}$ are electronegative and both molecules have a polar structure. On the other hand, heavy hydrocarbons have a high chance that their molecular electron density will not be evenly distributed [17]. This uneven distribution causes a temporary multi-pole state in heavy hydrocarbons, leading to attraction by $\mathrm{CO}_{2}$ and $\mathrm{H}_{2} \mathrm{~S}$ molecules in the gas phase. The chance of distributing in electron density will be stronger by presenting $\mathrm{CO}_{2}$ and $\mathrm{H}_{2} \mathrm{~S}$ and longer chains of carbons in hydrocarbon molecules. So, heavy hydrocarbons will have a greater tendency to revaporize and produce a phase when $\mathrm{CO}_{2}$ and $\mathrm{H}_{2} \mathrm{~S}$ exist in storage gas.

To show this effect, the Condensate Holding Ratio (CHR) of injected gas is defined as the ratio of condensate in injected sour gas in equilibrium with reservoir fluid to that in pure $\mathrm{CH}_{4}$ (as a base component for storage gas) in equilibrium with reservoir fluid. The CHR can be defined as Equation (2):

$$
C H R=\frac{y_{\mathrm{C}_{5+}}^{i n j}}{y_{\mathrm{C}_{5+}}^{\mathrm{CH}_{4}}}
$$

The CHR can be interpreted as a function of the condensate equilibrium ratio, called the $K$-value in terms of classical thermodynamics. The $K$-value of condensate $\left(\mathrm{C}_{5+}\right)$ in the mixture of injected gas is defined as Equations (3) and (4) for storage of sour and pure methane, respectively:

$$
K_{\mathrm{C}_{5+}}^{\text {sour }}=\frac{y_{\mathrm{C}_{5+}}^{\text {sour }}}{x_{\mathrm{C}_{5+}}^{\text {sour }}}
$$

$$
K_{\mathrm{C}_{5+}}^{\text {pure }}=\frac{y_{\mathrm{C}_{5+}}^{\text {pure }}}{x_{\mathrm{C}_{5+}}^{\text {pure }}}
$$

Also, the mole fraction of condensate in the gas phase for each state is obtained by rearrangement of Equations (3) and (4):

$$
\begin{aligned}
& y_{\mathrm{C}_{5+}}^{\text {sour }}=K_{\mathrm{C}_{5+}}^{\text {sour }} x_{\mathrm{C}_{5+}}^{\text {sour }} \\
& y_{\mathrm{C}_{5+}}^{\text {pure }}=K_{\mathrm{C}_{5+}}^{\text {pure }} x_{\mathrm{C}_{5+}}^{\text {pure }}
\end{aligned}
$$

By substituting Equations (5) and (6) in (2), the Condensate Holding Ratio is obtained, as follows:

$$
C H R=\frac{K_{\mathrm{C}_{5+}}^{\text {sour }} x_{\mathrm{C}_{5+}^{\text {sou }}}}{K_{\mathrm{C}_{5+}}^{\text {pure }} x_{\mathrm{C}_{5+}}^{\text {pure }}}
$$

$\mathrm{C}_{5+}$ is the major constituent of the reservoir liquid phase and accounts for more than $85 \mathrm{~mole} \%$, regardless of the type of storage injection gas. Therefore, changes in the mole fraction of $\mathrm{C}_{5+}$ in sour gas injection and pure methane injection can be assumed to be negligible. By this assumption Equation (7) changes as:

$$
C H R=\frac{K_{\mathrm{C}_{5+}}^{\text {sour }}}{K_{\mathrm{C}_{5+}}^{\text {pure }}}
$$

Values of the CHR and $K$-value of condensate $\left(\mathrm{C}_{5+}\right)$ for several types of storage gas were calculated by using the Peng-Robinson Equation of State (PR-EOS) and are shown in Figures 7 and 8. Figure 7 shows that the presence of $\mathrm{CO}_{2}$ and $\mathrm{H}_{2} \mathrm{~S}$ in injected gas increases the $K$-value of the condensate. Also, it can be deduced from these figures that the effect of $\mathrm{H}_{2} \mathrm{~S}$ is superior to $\mathrm{CO}_{2}$. A similar trend is observed in the CHR, as shown in Figure 8. This figure also 


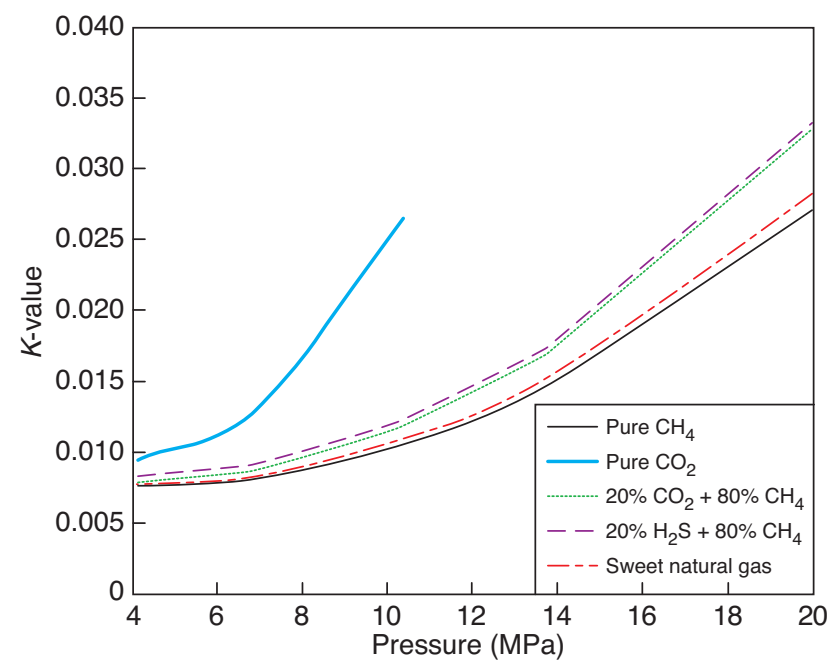

Figure 7

$K$-value of condensate $\left(\mathrm{C}_{5+}\right)$ for different types of storage gas.

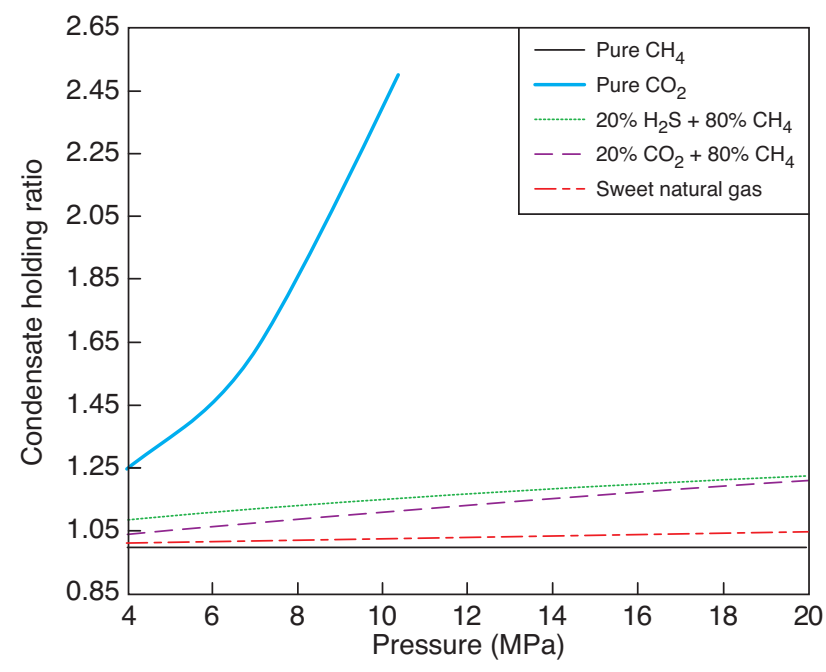

Figure 8

CHR for different types of storage gas at $77.22^{\circ} \mathrm{C}$. shows that injection of pure $\mathrm{CO}_{2}$ increases the condensate production drastically more than other streams. Previous studies $[6,9]$ confirmed this trend.

Melean et al. [9] studied the effects of thermodynamic conditions on the interfacial properties. Relevant parameters which they studied are dimensionless Bond number and capillary number to relative interfacial properties to gravity and viscous forces, respectively. Their study shows that $\mathrm{CO}_{2}$ is more effective in lowering gas/oil IFT, followed by $\mathrm{CH}_{4}$ and $\mathrm{N}_{2}$. Therefore, the condensate phase loses its tendency to remain on the surface of the water phase that often covers the porous rock. As a result, heavier hydrocarbon is ready to vaporize and produce with the gas phase during the withdrawal stage of successive UGS cycles.

\subsection{Effect of $\mathrm{H}_{2} \mathrm{~S} \& \mathrm{CO}_{2}$ Impurities on the Heating Value}

One of the most important factors in UGS projects is the study of the difference in the heating value of injected and produced gas streams during Injection/ Withdrawal cycles. To achieve this purpose, the heating value of produced gas was calculated in all I/W cycles and compared with the heating value of injected gas. The heating value of a gas stream is calculated by multiplying the heating value of each component into its mole fraction. The heating value of defined components such as $\mathrm{CH}_{4}, \mathrm{C}_{2} \mathrm{H}_{6}$ and $\mathrm{C}_{3} \mathrm{H}_{8}$ are obtained from the GPSA book [12]. Other components are assumed to be paraffinic components and their heating values are calculated by interpolating between defined and available paraffinic component heating values with molecular weight in the range near to the heavy components.
To study the effect of the presence of $\mathrm{H}_{2} \mathrm{~S}$ and $\mathrm{CO}_{2}$ in injected gas on the heating value of produced gas, the ratio of difference between the produced and injected gas streams' heating value to the injected gas's heating value are calculated. As shown in Figure 9, the difference between the heating value of produced and injected gas increases with the increase in $\mathrm{H}_{2} \mathrm{~S}$ and $\mathrm{CO}_{2}$ content of the injected gas. A gas stream with a $10 \% \mathrm{H}_{2} \mathrm{~S}$ mole fraction has a higher difference between the heating value of injected and produced gas compared with other gas streams. This figure also shows that the heating value of produced gas increases during production in each $\mathrm{I} / \mathrm{W}$ cycle because the heavy component mole fraction in the production gas stream increases with pressure decline. On the other hand, because of the decrease in total heavy components within the depleted reservoir during I/W cycles, production of heavy components decreases; so, the heating value of produced gas decreases.

Also, Figure 10 compares the heating values for different streams of injection and production in which the heating value of sweet streams is higher than that of sour streams.

\subsection{Effect of $\mathrm{H}_{2} \mathrm{~S}$ and $\mathrm{CO}_{2}$ Impurities on Pressure Rise}

As the reservoir is volumetric with no active aquifer, the difference between the $z$-factor of injected and reservoir fluid was found to be the main cause for pressure rise during successive I/W cycles [2]. The vaporizing-gas displacement process derives from the fact that the injected dry gas with a lower specific gravity and higher $z$-factor compared with the reservoir fluid is enriched by vaporizing intermediate and heavy components from the condensate liquid. As a result, residual reservoir fluid becomes leaner and its $z$-factor starts 


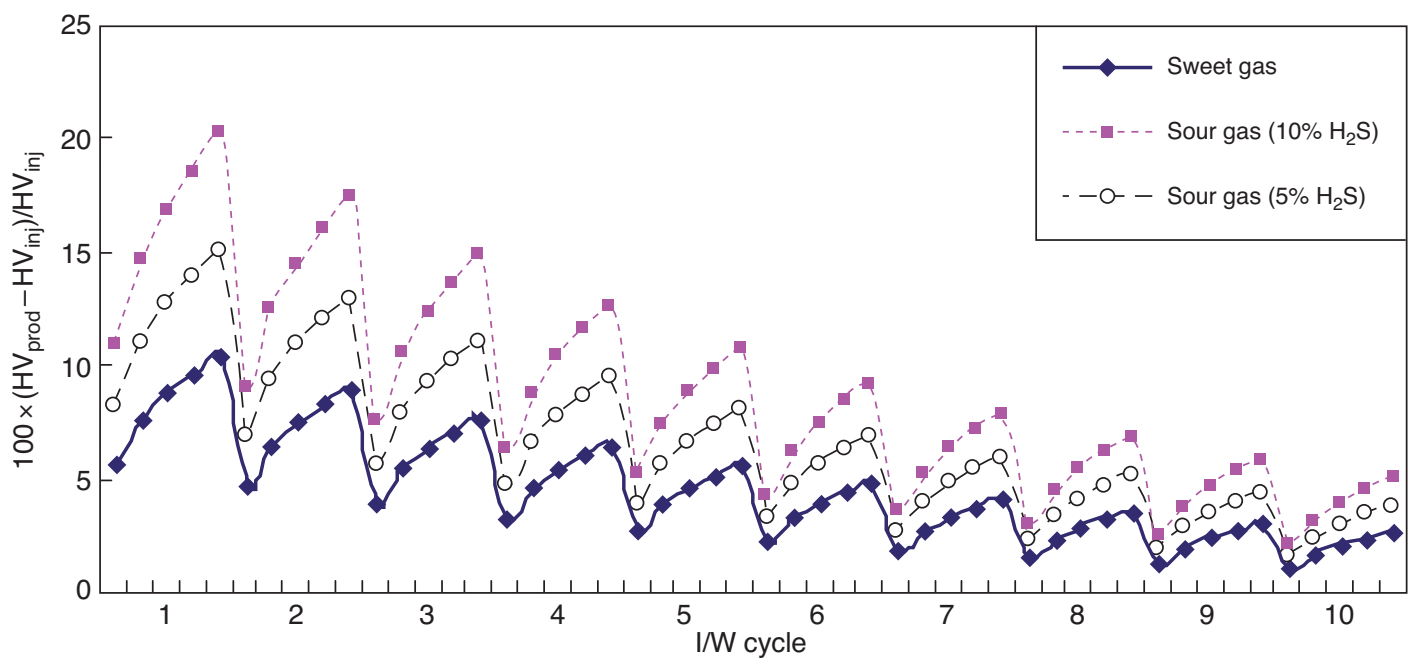

Figure 9

Ratio of difference between heating value of produced and injected gas streams to heating value of injected gas stream in each I/W cycle.

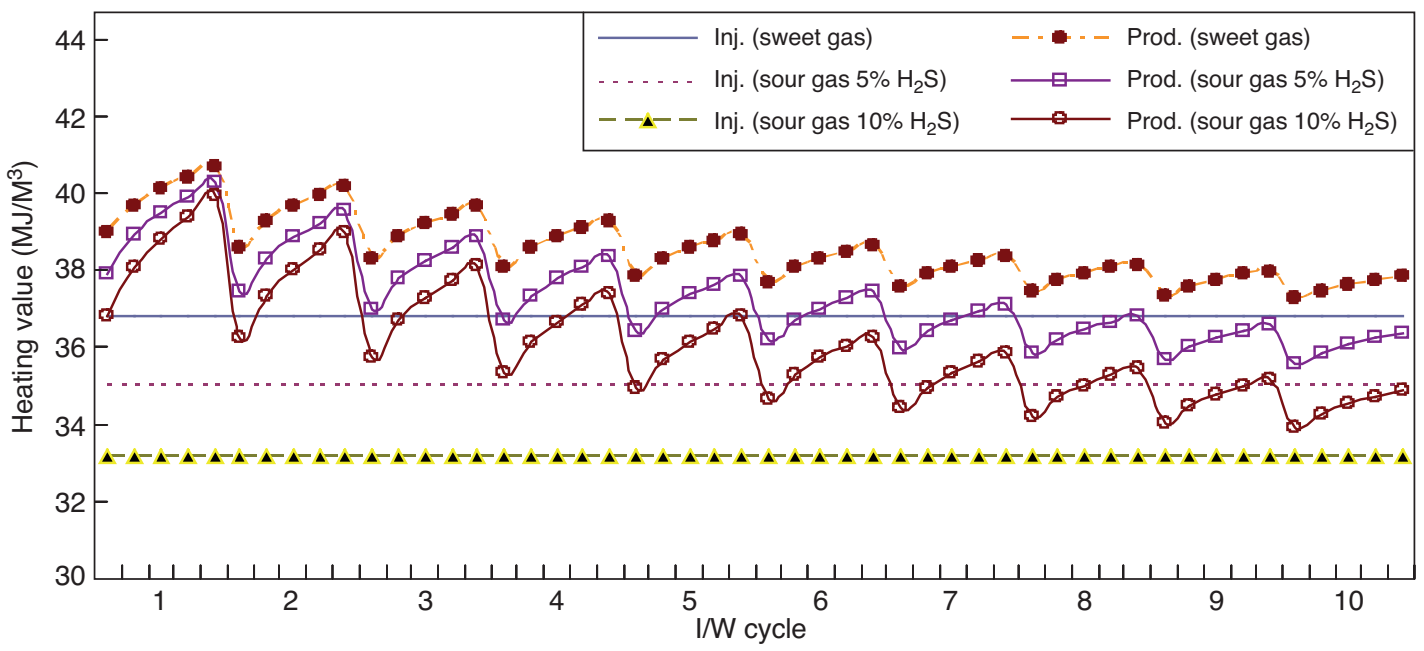

Figure 10

Heating value of injection and production streams versus successive I/W cycles.

to increase. Subsequently, reservoir pressure will slowly rise at the end of I/W cycles [2]. The $z$-factor of injection and reservoir fluid was calculated through numerical representation of the Standing and Katz [13] $z$-factor graph offered by Dranchuk and Abou-Kassem equations [14].

It is well known that existence of $\mathrm{CO}_{2}$ and $\mathrm{H}_{2} \mathrm{~S}$ leads to large errors in the evaluation of the compressibility factor. The remedy to this problem is to adjust the pseudo-critical properties to account for the unusual behavior of these components. The equations used for this adjustment are [15]:

$$
T_{p c}=T_{p c}-\varepsilon
$$

$$
P_{p c}^{\prime}=\frac{P_{p c} T_{p c}^{\prime}}{T_{p c}+y_{\mathrm{H}_{2} \mathrm{~S}}\left(1-y_{\mathrm{H}_{2} \mathrm{~S}}\right) \varepsilon}
$$

$T_{p c}{ }^{\prime}$ and $P_{p c}$ are then used to calculate $T_{p r}$ and $P_{p r}$ for a sour gas stream. The pseudo-critical temperature adjustment factor $\varepsilon$ is obtained using a graphical procedure defined by Wichert and Royan [15]. The reduction of the compressibility $z$-factor caused by the presence of $\mathrm{CO}_{2}$ and $\mathrm{H}_{2} \mathrm{~S}$ is shown in Figure 11. As the acid gas content of the injection stream increases, the $z$-factor of the injection stream decreases at pressures of interest. 


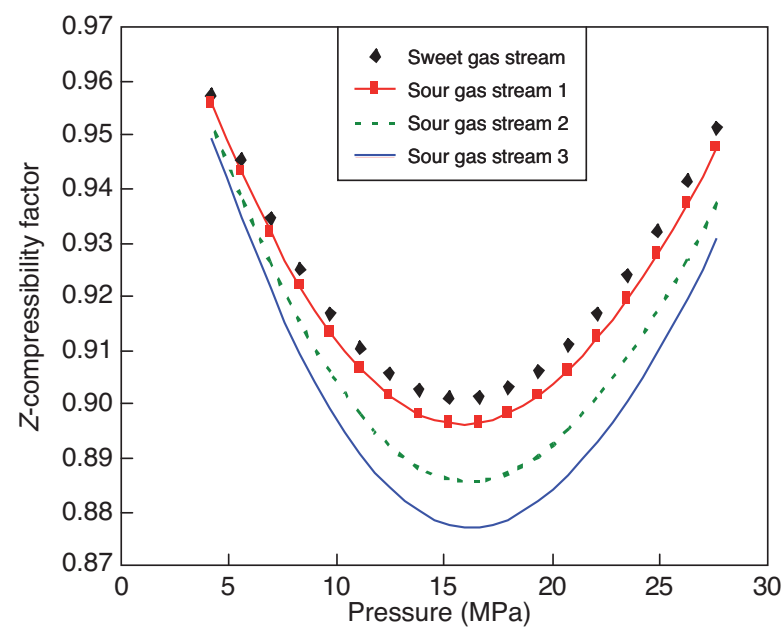

Figure 11

Compressibility $z$-factor trend versus pressure for different gas streams.
The results reveal that the UGS reservoir will experience a lower pressure rise at the end of I/W cycles when the mole fraction of $\mathrm{CO}_{2}$ and $\mathrm{H}_{2} \mathrm{~S}$ increases, because the difference between the $z$-factors of injected and reservoir fluids is smaller. However, the reservoir pressure differences among the sweet gas and three sour gas streams are small because of a small amount of $\mathrm{CO}_{2}$ and $\mathrm{H}_{2} \mathrm{~S}$ in the gas streams. This fact is illustrated in Figures 12 and 13. Figure 12 represents that maximum and minimum of operating pressure during each injection/withdrawal cycle take place between $16 \mathrm{MPa}$ and less than $21 \mathrm{MPa}$ as it was expected beforehand since base pressure and initial reservoir pressure for this specific reservoir were 15.86 and $21.37 \mathrm{MPa}$ respectively. Reservoir pressure difference among different streams can be observed more accurately in Figure 13, in which only pressure at the end of I/W cycles has been plotted versus time. Figure 14 summarizes calculation of changes in the $z$-factor of injected

Figure 12

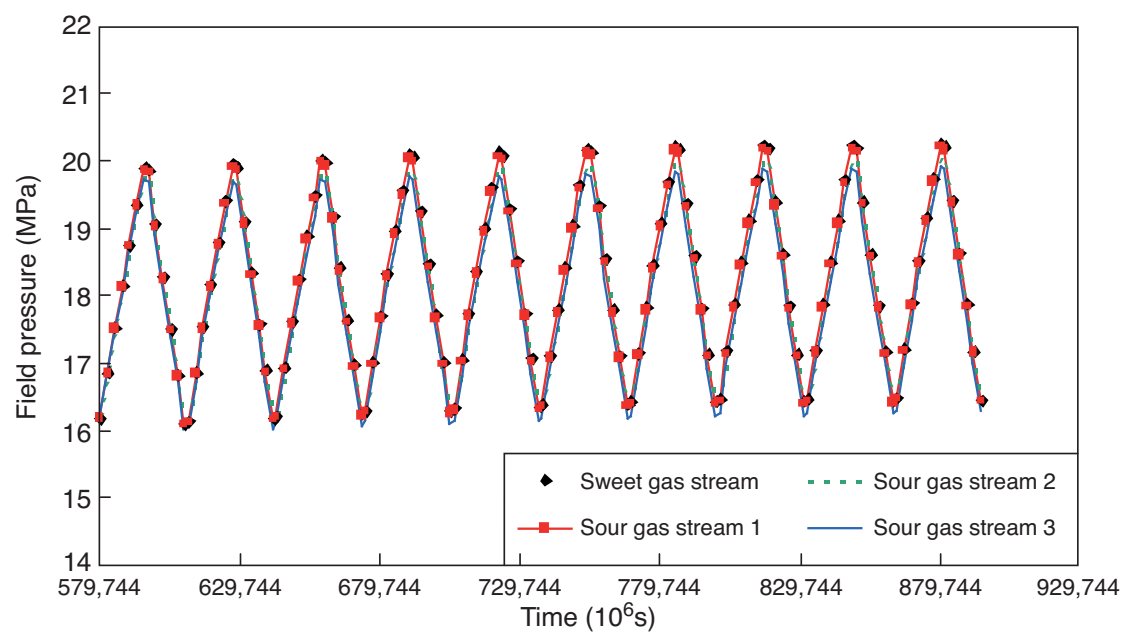

Pressure trend versus time for different injected streams during successive I/W cycles.

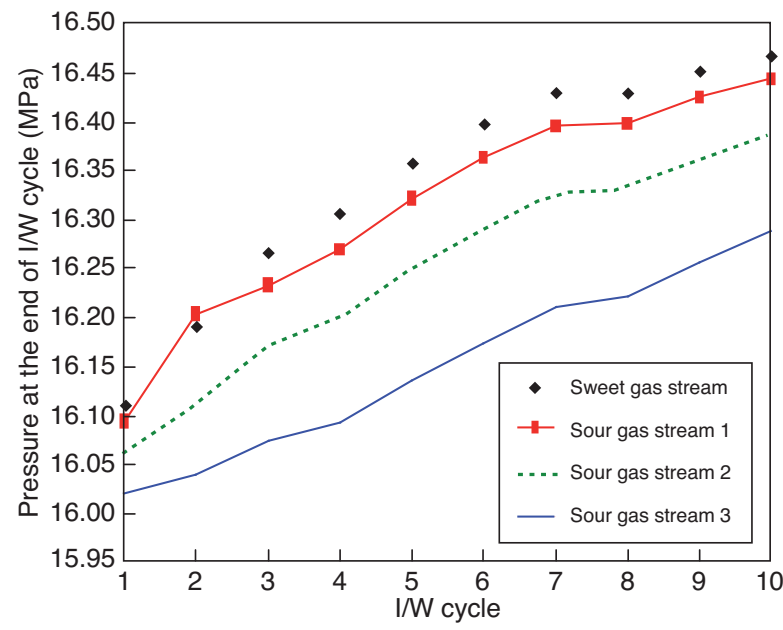

Figure 13

Pressure rise at the end of successive I/W cycle for different compositions of injected gas streams.

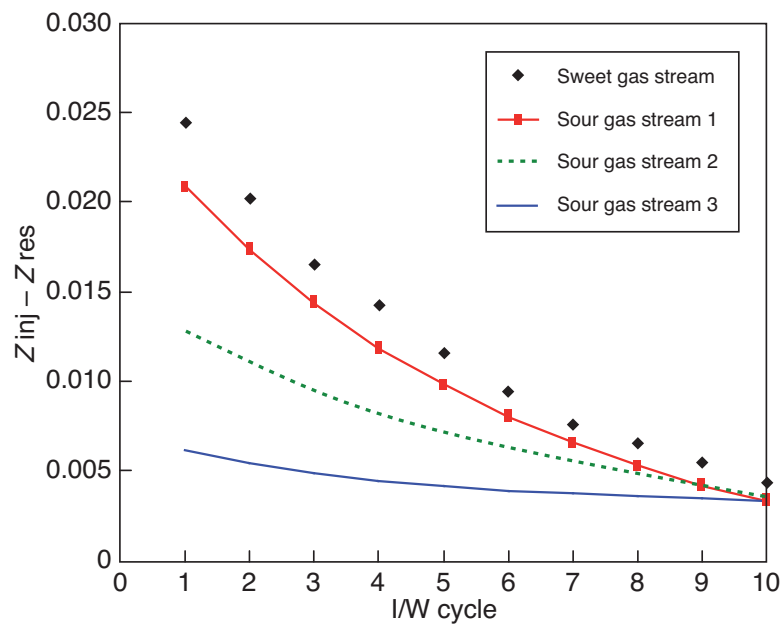

Figure 14

Difference between compressibility $z$-factor of injected gas and reservoir fluids during $\mathrm{I} / \mathrm{W}$ storage cycles. 
gas and reservoir fluid at different pressures for all cycles. The difference between the compressibility $z$-factor of injected gas and reservoir fluids declines during storage cycles because the composition of the reservoir fluid approaches that of the injected fluid.

\section{CONCLUSIONS}

- Condensate Production Enhancement (CPE) has a higher rate in earlier cycles and declines in later UGS cycles;

- the Condensate Holding Ratio (CHR) is higher in sour gas injection compared with sweet gas injection, resulting in higher condensate recovery;

- as the composition of $\mathrm{CO}_{2}$ and $\mathrm{H}_{2} \mathrm{~S}$ increases in the injected gas stream, the difference between the heating value of produced and injected gas tends to increase;

- because of heavy component production at the surface, the heating value of produced gas increases in each $\mathrm{I} / \mathrm{W}$ cycle. Meanwhile, the reduction in the amount of remaining heavy hydrocarbons within the reservoir causes the heating value of produced gas to be higher at earlier stages of UGS compared with later ones;

- the presence of $\mathrm{CO}_{2}$ and $\mathrm{H}_{2} \mathrm{~S}$ components in the injection gas stream decreases the compressibility $z$-factor of the injection stream and causes less pressure rise than that without any trace of $\mathrm{CO}_{2}$ and $\mathrm{H}_{2} \mathrm{~S}$;

- the difference between the compressibility $z$-factor of injected gas and reservoir fluids has a smaller value in the case of sour gas streams.

\section{REFERENCES}

1 Tureyen O.I., Karaalioglu H., Satman A. (2000) Effect of the Wellbore Conditions on the Performance of Underground GasStorage Reservoirs, SPE 59737, SPE/CERI Gas Technology Symposium, Calgary, Alberta, Canada, 3-5 April.

2 Azin R., Nasiri A., Jodeyri Entezari A. (2008) Investigation of Underground Gas Storage in a Partially Depleted Gas Reservoir, J. Oil Gas Sci. Technol. 63, 691-703.
3 Jodeyri Entezari A., Azin R., Nasiri A., Bahrami H. (2010) Investigation of Underground Gas Storage in a Partially Depleted Naturally Fractured Gas Reservoir, Iran. J. Chem. Chem. Eng. 29, 1, 103-110.

4 Malakooti R., Azin R. (2011) Optimization of Underground Gas Storage in a Partially Depleted Gas Reservoir, J. Pet. Sci. Technol. 29, 824-836.

5 Adel H., Tiab D., Zhu T. (2006) Effect of Gas Recycling on the Enhancement of Condensate Recovery, Case Study: Hassi R' Mel South Field, Algeria, SPE 104040, First International Conference and Exhibition, Cancun, Mexico, 31 August-2 September.

6 Zaitsev I.Y., Dmitrievsky S.A., Norvik H., Yufin P.A., Bolotnik D.N., Sarkisov G.G., Schepkina N.E. (1996) Compositional Modeling and PVT Analysis of Pressure Maintenance Effect in Gas Condensate Field: Comparative Study, SPE 36923, SPE European Petroleum Conference, Milan, Italy, 22-24 October.

7 Clark M.A. (1999) Experimentally Obtained Saturated Water Content, Phase Behavior and Density of Acid Gas Mixtures, MSc Thesis, University of Calgary, Canada.

8 Seto C.J., Jessen K., Orr Jr F.M. (2003) Compositional Streamline Simulation of Field Scale Condensate Vaporization by Gas Injection, SPE 79690, SPE Reservoir Simulation Symposium, Houston, Texas, USA, 3-5 February.

9 Melean Y., Bureau N., Broseta D. (2001) Interfacial Effects in Gas-Condensate Recovery and Gas Injection Processes, SPE 71495, SPE Annual Technical Conference and Exhibition, New Orleans, Louisiana, USA, 30 September-3 October.

10 Wichert E., Aziz K. (1972) Calculate Zs for Sour Gases, Hydrol. Process. 51, 119-122.

11 Schlumberger, Eclipse Reference Manual, Houston, TX, Schlumberger Information Solution, 2005.

12 Physical Properties, Engineering Data Book, Gas Processors Suppliers Association, Tulsa, Okvtv, 1998.

13 Standing M.B., Katz D.L. (1942) Density of Natural Gases, Trans. AIME 146, 140-149.

14 Dranchuk P.M., Abou-Kassem J.H. (1975) Calculation of $z$-Factors for Natural Gases Using Equations of State, J. Can. Pet. Technol. 14, 34-36.

15 Wichert E., Royan T. (1997) Acid Gas Injection Eliminates Sulfur Recovery Expense, J. Oil Gas 95, 17, 67-72.

16 http://www.NIGC.ir, 23/07/2009.

17 http://en.wikipedia.org/wiki/London_dispersion_force, 2/09/2010.

Final manuscript received in September 2011 Published online in February 2013 or distributed for profit or commercial advantage and that copies bear this notice and the full citation on the first page. Copyrights for components of this work owned by others than IFP Energies nouvelles must be honored. Abstracting with credit is permitted. To copy otherwise, to republish, to post on servers, or to redistribute to lists, requires prior specific permission and/or a fee: Request permission from Information Mission, IFP Energies nouvelles, fax. +33147527096, or revueogst@ifpen.fr. 